\title{
Vibration Test and Shock Absorption of Coal Crusher Chambers in Thermal Power Plants (I): Field Test and Assessment
}

\author{
Lihua Zhu ${ }^{\mathbb{D}},{ }^{1,2}$ Hanquan Yuan, ${ }^{1}$ Haoyi Zhou, ${ }^{1}$ Dong Jiang, ${ }^{3}$ Baoquan Liu, ${ }^{3}$ Chunzhu Fan, ${ }^{3}$ \\ and Liujiu Tang ${ }^{3}$ \\ ${ }^{1}$ School of Civil Engineering, Xi'an University of Architecture \& Technology, 13 Yanta Road, Xi'an 710055, China \\ ${ }^{2}$ Key Lab of Structural Engineering and Earthquake Resistance, Ministry of Education (XAUAT), Xi'an 710055, China \\ ${ }^{3}$ Northwest Electric Power Design Institute Co., Ltd. of China Power Engineering Consulting Group, Xi'an 710075, China \\ Correspondence should be addressed to Lihua Zhu; zhulihuaxa@163.com
}

Received 21 July 2020; Revised 15 September 2020; Accepted 9 October 2020; Published 28 October 2020

Academic Editor: Ömer Cívalek

Copyright ( $\odot 2020$ Lihua Zhu et al. This is an open access article distributed under the Creative Commons Attribution License, which permits unrestricted use, distribution, and reproduction in any medium, provided the original work is properly cited.

A field vibration test was conducted on the coal crusher chamber of a thermal power plant to evaluate its vibration performance. The vibration displacements and velocities of the structure, coal crusher body, and vibration-isolation platform were tested. The vibration safety of the coal crusher chamber and the vibration-isolation efficiency of the spring vibration-isolation system were evaluated based on the test results, and the reason the vibration exceeded the limit was analyzed. This study showed that the vibration displacement of a coal crusher with a spring vibration-isolation system met the code requirements, but the equipment had greater vibration displacements, which were related to the connection between the equipment and the platform. Compared to a steel platform, the vibration displacement of a concrete platform was smaller, and the vibration-isolation efficiency was greater. The vibration displacements of the coal crusher body could be reduced by controlling the vibration displacements of the platform.

\section{Introduction}

Coal crushers are important auxiliary dynamic machines in thermal power plants and are used for crushing and processing raw coal. However, a coal crusher generates large vibrations when crushing coal blocks, which can affect the equipment itself, as well as the safety of the structure $[1,2]$. Although there have been few studies on the vibrations caused by coal crushers, the research done on the vibrations caused by similar dynamic machines can be used to study them [3-6]. Liang conducted a static analysis, dynamic analysis, and vibration control analysis of a crusher's foundation and discussed the main factors affecting the dynamic response of the dynamic machine's foundation [7]. However, only the foundation model of the crusher is established and applies the disturbing force of the crusher onto the foundation of the dynamic analysis, which is different from practical engineering. Liu et al. regarded the dynamic machine foundation and its surrounding structures are considered as a complete coupling object and proposed a three-dimensional finite element method for calculating the dynamic response of a large machine based on soil-structure interaction, and the main factors affecting its dynamic response are discussed [8]. Similarly, Zhu et al. considered the mill and its foundation as a coupled system and conducted vibration performance tests and evaluations of mediumspeed mills in thermal power plants [9]. The results showed that a spring damping system could effectively reduce the transmission of the mill's vibration to the outside. So far, researchers usually use field tests and numerical analysis methods to study the structural vibrations caused by machine vibration [10]. Wang et al. determined the cause of vibrations using a field vibration test and numerical analysis in a plant [11]. On the basis of this numerical analysis, a method for secondary vibration isolation and reinforcement was proposed to provide a reference for reducing the vibration and reinforcing existing structures to withstand abnormal vibration.

Gazetas believed that the basic goal of dynamic machine foundation design was to reduce its vibration amplitude to 
ensure safe operation and avoid affecting work on nearby equipment [12]. This guiding ideology has been adopted by the design codes of most countries in the world. Most of the engineering technicians in China address the structural vibration problems caused by dynamic machines based on the guidance provided by the "Code for design of dynamic machine foundation" (GB 50040-1996) [13] and other specifications. In practical engineering, many engineering technicians use two methods to reduce structural vibration: increasing the rigidity and quality of the coal crusher chamber and machine foundation and using a coal crusher vibration-isolation platform. Because the vibration of the coal crusher chamber is very complicated, even if these two design countermeasures are adopted, the vibration problem still exists for the coal crusher chamber. Even when using the same design scheme and machine parameters, the vibration problem for the coal crusher chamber is more prominent in some power plants, whereas other vibrations are very small. This problem has always puzzled designers. In-depth research is needed to understand the structure of the coal crusher chamber and the vibration behavior of the coal crusher further.

In this study, vibration tests were performed on coal crusher chambers in three power plants, and the safety of the equipment and structure was evaluated based on the test results. In addition, the vibration-isolation efficiency of the spring vibration-isolation system was calculated. These data provided a basis for finite element modeling.

\section{Description of Coal Crusher Chamber}

In general, the coal crusher chamber of a thermal power plant utilizes a four-story reinforced concrete frame structure. The first story is the pipeline layer, the second story is the coal crusher layer, the third story is the vibrating screen layer, and the fourth story is the coal handling layer, as shown in Figure 1. The coal crusher system is composed of the coal crusher, motor, and hydraulic coupler. It is located on the second story of the coal crusher chamber and is connected to the coal crusher chamber through the spring vibration-isolation system, as shown in Figure 2. The spring vibrationisolation system consists of a vibration-isolation platform and spring vibration isolator, in which the vibration-isolation platform can be either a concrete platform or a steel platform. Compared with a concrete platform, a steel platform has a smaller volume, lighter weight, and higher cost. The spring vibration isolator is an elastic element between the machine and the support structure [14]. This elastic element is composed of a spiral steel spring with damping treatment, which is designed to reduce the vibration or impact force from the machine to the support structure. Generally, the spring vibration isolator is used with a viscous damper to prevent the vibration amplitude of the machine from being excessive when starting and stopping.

\section{Field Tests}

3.1. Coal Crusher System and Vibration-Isolation Platform. Three coal crushers in the Linyou, Shangluo, and Ezhou power plants in China were tested to investigate their vibration performances. These three plants all used the spring vibration-isolation system for their coal crushers. Steel platforms were used for the coal crushers in the Linyou and Shangluo power plants, and a concrete platform was used for the coal crusher in the Ezhou power plant. The primary parameters of the coal crusher systems and vibration-isolation platforms are listed in Table 1.

3.2. Test Program. The primary instruments used in this test included $941 \mathrm{~B}$ vibration pickups, an amplifier with a frequency response range of $0.5-100 \mathrm{~Hz}$, and an INV306 intelligent signal collecting and processing analyzer. The analysis and processing of the collected data relied on the DASP program.

The Shangluo power plant will be considered as an example. The test program used at the other two power plants was the same as that used at the Shangluo power plant.

A modal test of the coal crusher chamber, vibration test of the structure and machine, and vibration-isolation efficiency test of the spring vibration-isolation system were performed. The modal test of the structure used the pulsation method to determine the natural frequency of the structure by placing horizontal vibration sensors on the first floor, second floor, third floor, fourth floor, and the roof, as shown in Figure 3. Five measurement points were also used to determine the vibration displacements and velocities of the structure and machine. Among these, TP1 was a measurement point on the floor slab located near the coal crusher. TP2 was the midpoint on the long side of the top of the coal crusher. TP3 was the midpoint on the short side of the coal crusher, and TP4 and TP5 were measurement points on the vibration-isolation platform, as shown in Figure 4.

After considering site conditions, the layout characteristics of the spring vibration isolator, the measurability of the desired data, and the dynamic characteristics of the crusher, there were eight groups of spring vibration isolators tested $(\mathrm{A}-\mathrm{H})$, as shown in Figure 5 . In the coordinate system of the coal crusher chamber, $X$ represents the transverse direction, $Y$ represents the longitudinal direction, and $Z$ represents the vertical direction.

3.3. Test Results. Modal tests were conducted after the coal crusher was shut down, and the natural frequency and damping ratio were measured using the vibration sensors. The data were analyzed in the frequency domain using the DASP program, and the results are listed in Table 2.

As listed in Table 2, the first-order frequency in the horizontal direction was 0.987-1.625, and the second-order frequency was 2.587-3.012. The natural frequencies of the coal crusher chambers of the three power plants were relatively similar, which was a result of their similar structures. The measured value of the damping ratio was smaller than the value suggested by the code. Thus, the code suggested that a value of $5 \%$ could be used in the dynamic calculation.

Vibration tests were conducted during the steady operation stage of the coal crusher, with the vibration displacements and velocities measured using the described transducers. During the field test, it was found that the 


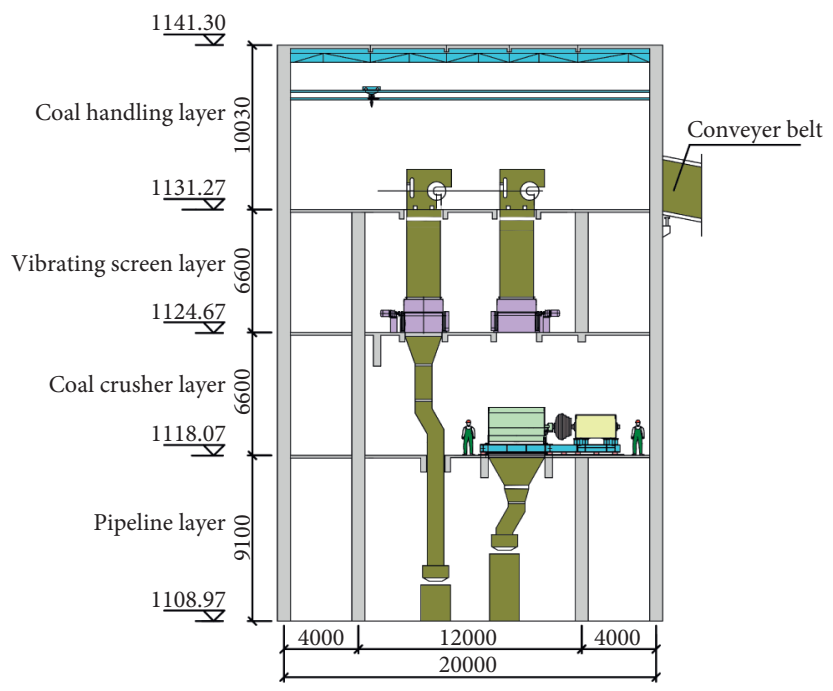

Figure 1: Coal crusher chamber.

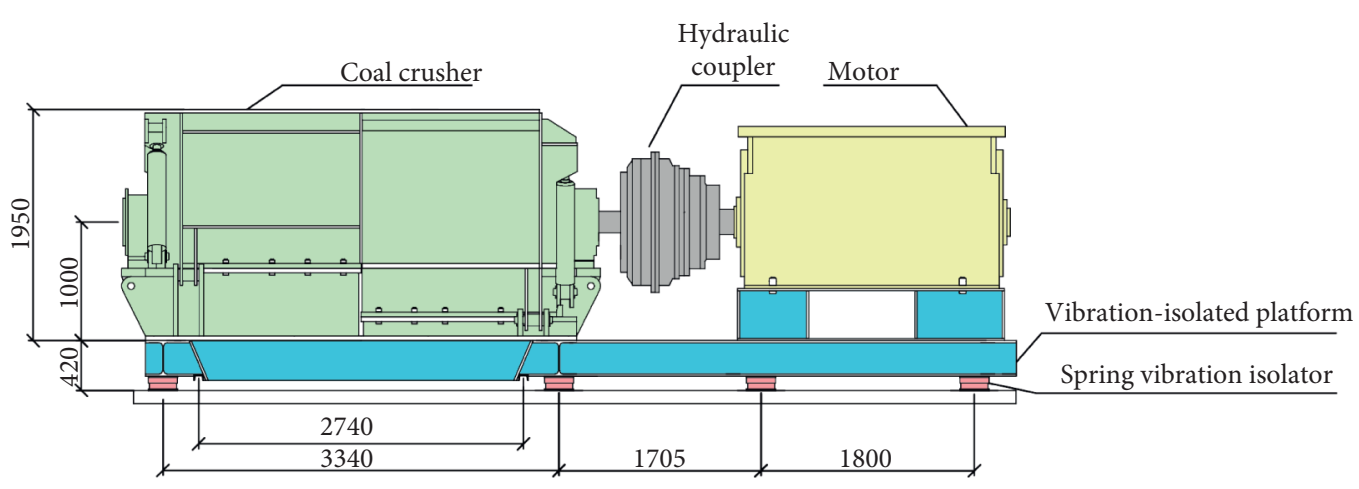

Figure 2: Coal crusher system.

TABLE 1: Technical parameters of coal crusher systems and vibration-isolation platforms.

\begin{tabular}{|c|c|c|c|c|}
\hline Parts & Parameters & Linyou power plant & Shangluo power plant & Ezhou power plant \\
\hline \multirow{3}{*}{ Coal crusher } & Type & $\mathrm{HCSC} 12$ & HM10-1630 & HCYS1000 \\
\hline & Rotation speed ( $\mathrm{r} / \mathrm{min})$ & 743 & 743 & 743 \\
\hline & Weight $(\mathrm{kg})$ & 32915 & 23500 & 30003 \\
\hline \multirow{3}{*}{ Motor } & Type & YXKK560-8 & YXKK630-8 & YKK5004-8 \\
\hline & Rotation speed (r/min) & 743 & 743 & 743 \\
\hline & Weight $(\mathrm{kg})$ & 6960 & 9200 & 6200 \\
\hline \multirow{2}{*}{ Hydraulic coupler } & Type & YOX1150 & YOX1250 & YOX1000 \\
\hline & Weight (kg) & 910 & 1166 & 650 \\
\hline Coal crusher system & Weight (kg) & 43554 & 33866 & 40871 \\
\hline Vibration-isolation platform & Weight $(\mathrm{kg})$ & 7502 & 8000 & 98892 \\
\hline
\end{tabular}

vibration amplitude of the coal crusher body in the Linyou power plant was very large. The noise in this plant, which included whistling caused by the crusher, was the largest of the three power plants. Serious powder leakage and large amounts of dust were also noted. The vibrations of the ground and platform in the Shangluo power plant were not serious, and only a small amount of dust was found. The vibration amplitude of the coal crusher body in the Ezhou power plant was the smallest; there was basically no powder leakage, and the plant was very clean. The test assumed that the vibrations of the floor, crusher body, and vibrationisolation platform were stable random processes and that the 


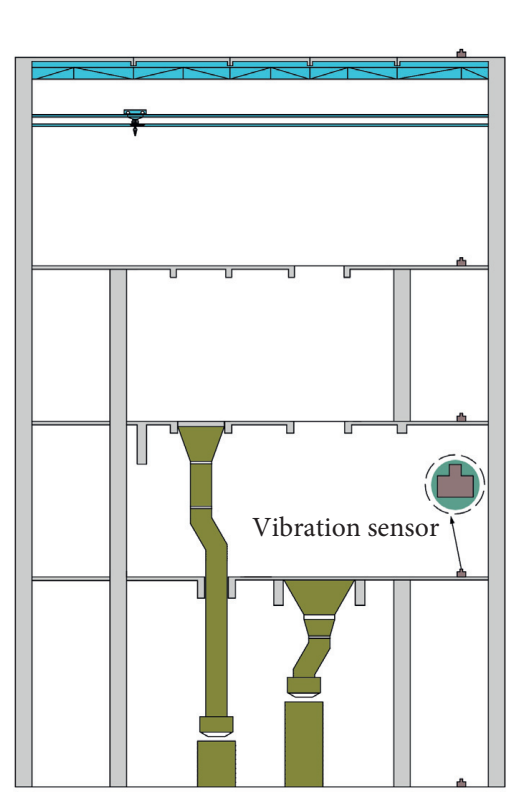

(a)

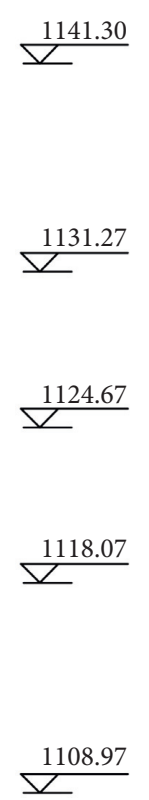

1108.97

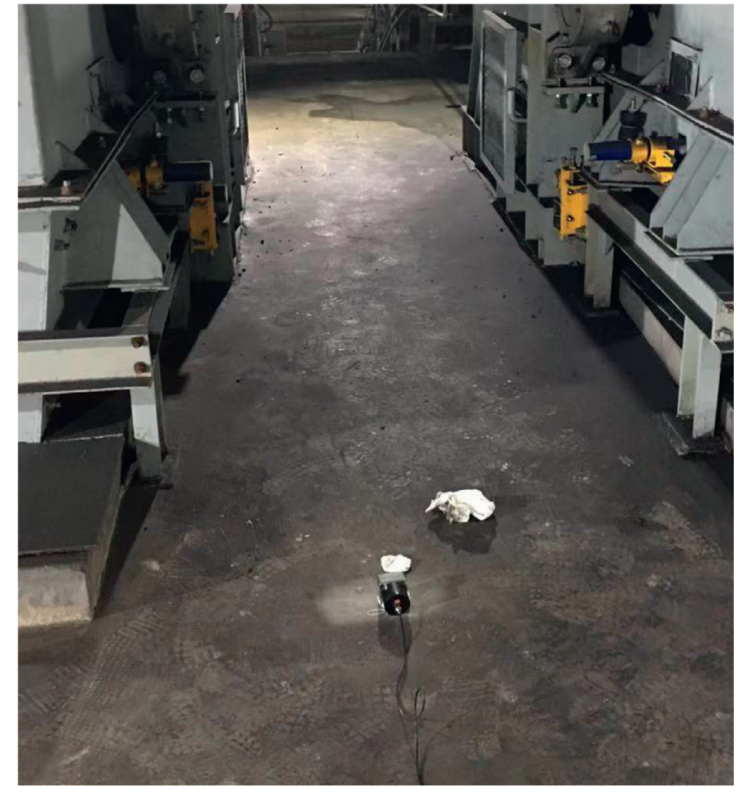

(b)

Figure 3: Modal test. (a) Arrangement of measurement points. (b) Vibration sensor on the second floor.

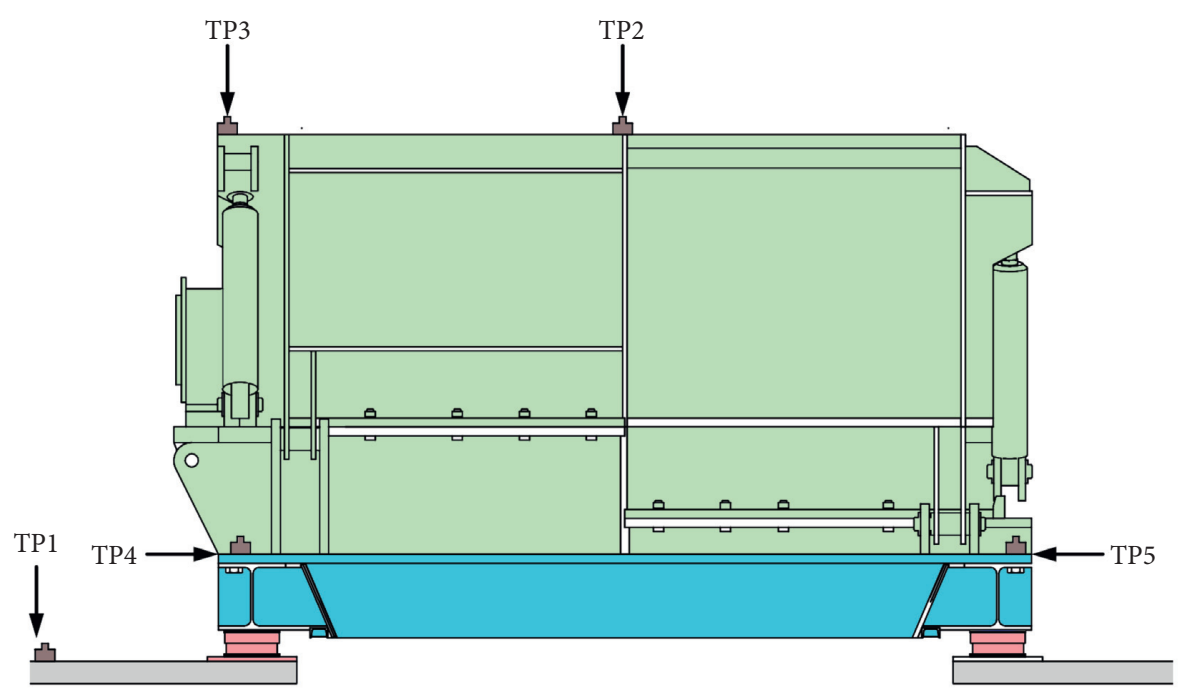

(a)

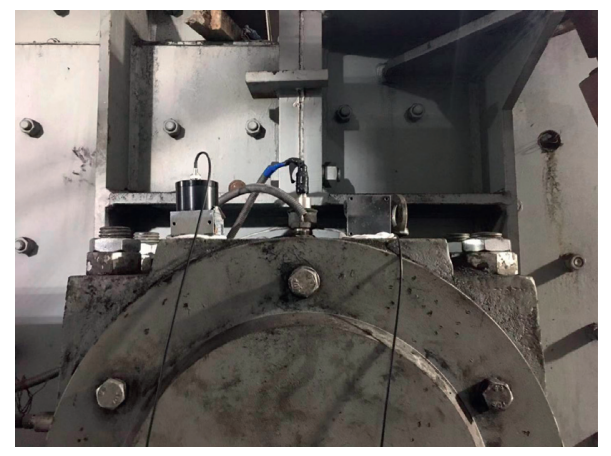

(b)

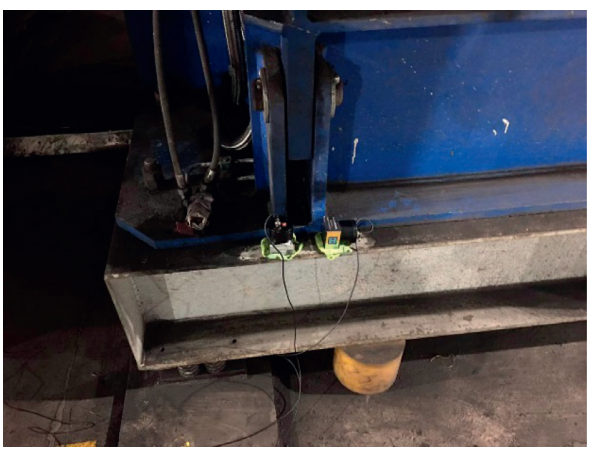

(c)

Figure 4: Vibration test. (a) Arrangement of measurement points. (b) Vibration sensor on the machine. (c) Vibration sensor on the platform. 


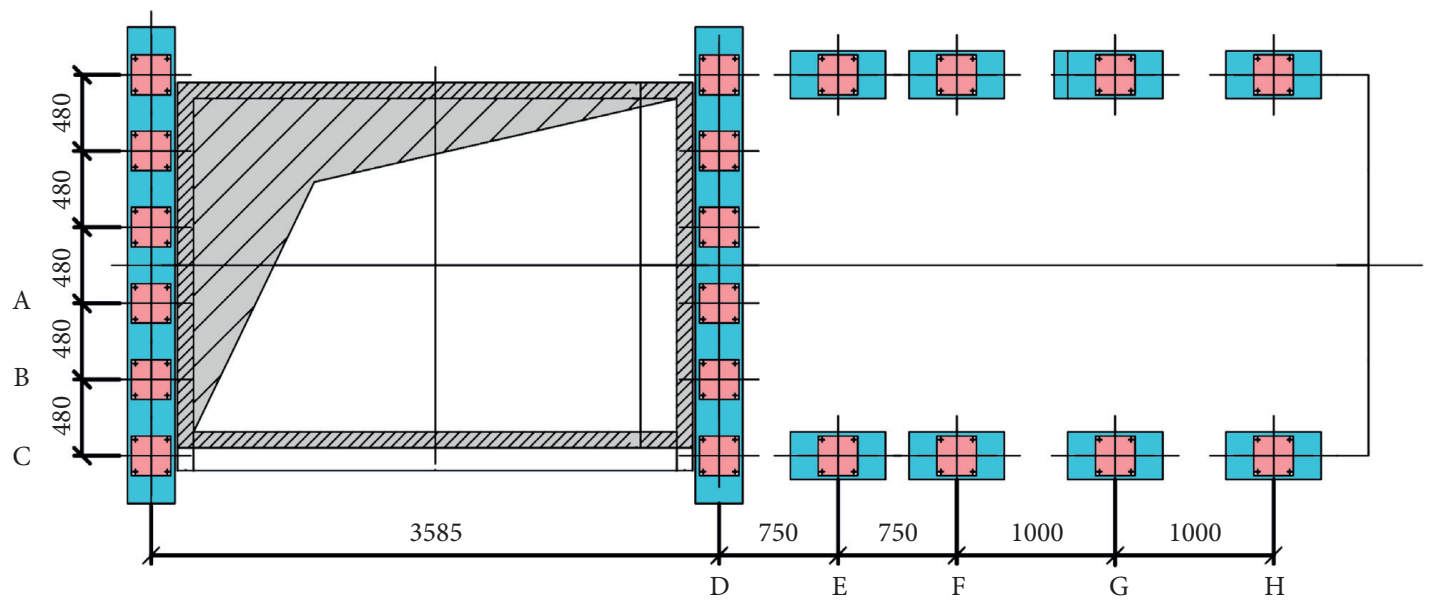

Figure 5: Position of the spring vibration isolators.

TABLE 2: Vibration frequency and damping ratio.

\begin{tabular}{lccccc}
\hline \multirow{2}{*}{ Power plant } & \multicolumn{3}{c}{ First modal shape } & \multicolumn{2}{c}{ Second modal shape } \\
& Direction & Frequency $(\mathrm{Hz})$ & Damping ratio (\%) & Frequency (Hz) & Damping ratio (\%) \\
\hline \multirow{2}{*}{ Linyou power plant } & $X$ & 1.563 & 0.353 & 2.851 & 0.226 \\
& $Y$ & 1.532 & 1.44 & 2.587 & 0.416 \\
\hline \multirow{2}{*}{ Shangluo power plant } & $X$ & 1.012 & 0.342 & 2.788 & 0.237 \\
& $Y$ & 0.987 & 0.822 & 3.012 & 0.240 \\
\hline \multirow{2}{*}{ Ezhou power plant } & $X$ & 1.475 & 0.726 & 2.712 & 0.255 \\
& $Y$ & 1.625 & & 0.251 \\
\hline
\end{tabular}

collected samples could reflect the vibration characteristics. Figure 6 shows the typical vibration curves of the coal crusher chamber, and the maximum value of the vibration is listed in Table 3. The test data provided a reference for the numerical analysis reported in part of this series of papers.

As listed in Table 3, the vibration displacement of the coal crusher body in the Linyou power plant was quite different from those in the other two power plants. This may have been due to differences in the design, manufacture, and installation of the machine body, which should be considered comprehensively.

\section{Assessment of Vibration Safety and Vibration-Isolation Efficiency}

4.1. Vibration of the Coal Crusher Chamber. The "Code for design of dynamic machine foundation" (GB 50040-1996) and "Technical code for the design of civil structure of fossil-fired power plant" (DL 5022-2012) [15] specify the following in relation to the maximum allowable amplitude for the coal crusher foundation: when the rotational speed of the machine, $n$, satisfies $n>750 \mathrm{r} / \mathrm{min}$, the allowable value in the vertical direction is $100 \mu \mathrm{m}$, and the allowable value in the horizontal direction is $150 \mu \mathrm{m}$. When $300 \mathrm{r} / \mathrm{min}<n \leq 750 \mathrm{r} / \mathrm{min}$, the allowable value in the vertical direction is $150 \mu \mathrm{m}$, and the allowable value in the horizontal direction is $200 \mu \mathrm{m}$. Out of consideration for human comfort, the "Code for design of building and structure of coal mine of preparation plant" (GB 50583-2010) [16] stipulates that the horizontal vibration velocity limit of the operating zone, where the power equipment directly acts, is $6.4 \mathrm{~mm} / \mathrm{s}$, and the vertical vibration velocity limit is $3.2 \mathrm{~mm} / \mathrm{s}$.

A comparison of the measured and allowable values is given in Table 4.

The speed of the three coal crushers in this test was $743 \mathrm{r} /$ min. Based on this, the maximum vibration displacements at the foundations of the coal crushers in the Shangluo and Ezhou power plants were all less than the allowable values. Thus, they all meet the vibration safety requirements. However, the maximum vertical vibration displacement of the coal crusher in the Linyou power plant was $219.39 \mu \mathrm{m}$, which exceeded the allowable value and did not meet the vibration safety requirements. The measurement point on the floor was near the coal crusher to determine the maximum vibration response of the floor slab near the coal crusher. These values for the three power plants were all less than the allowable value, which met the vibration safety requirements.

The lack of relevant guidelines on the vibration displacement of the machine body made it difficult to assess its 

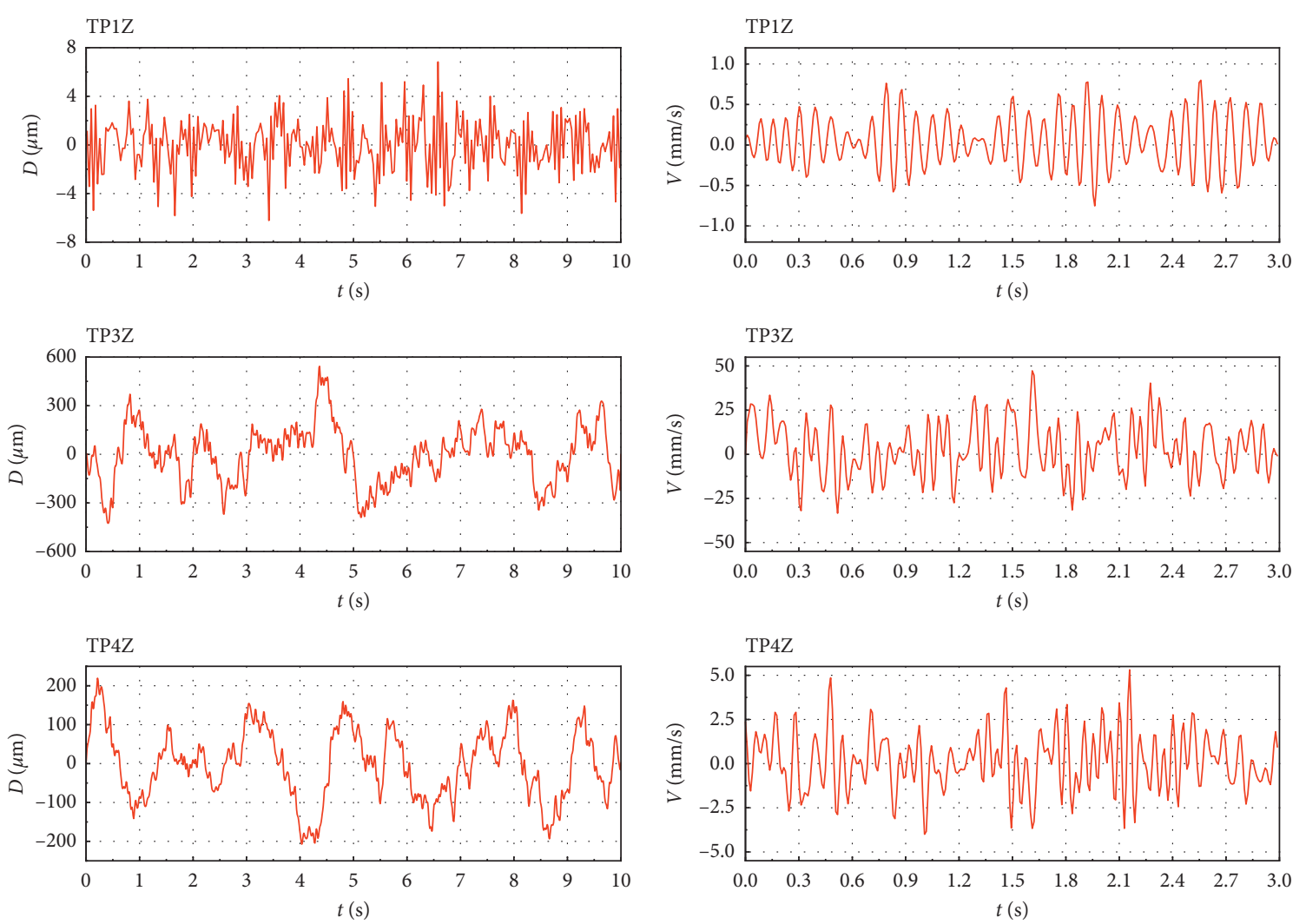

(a)

(b)
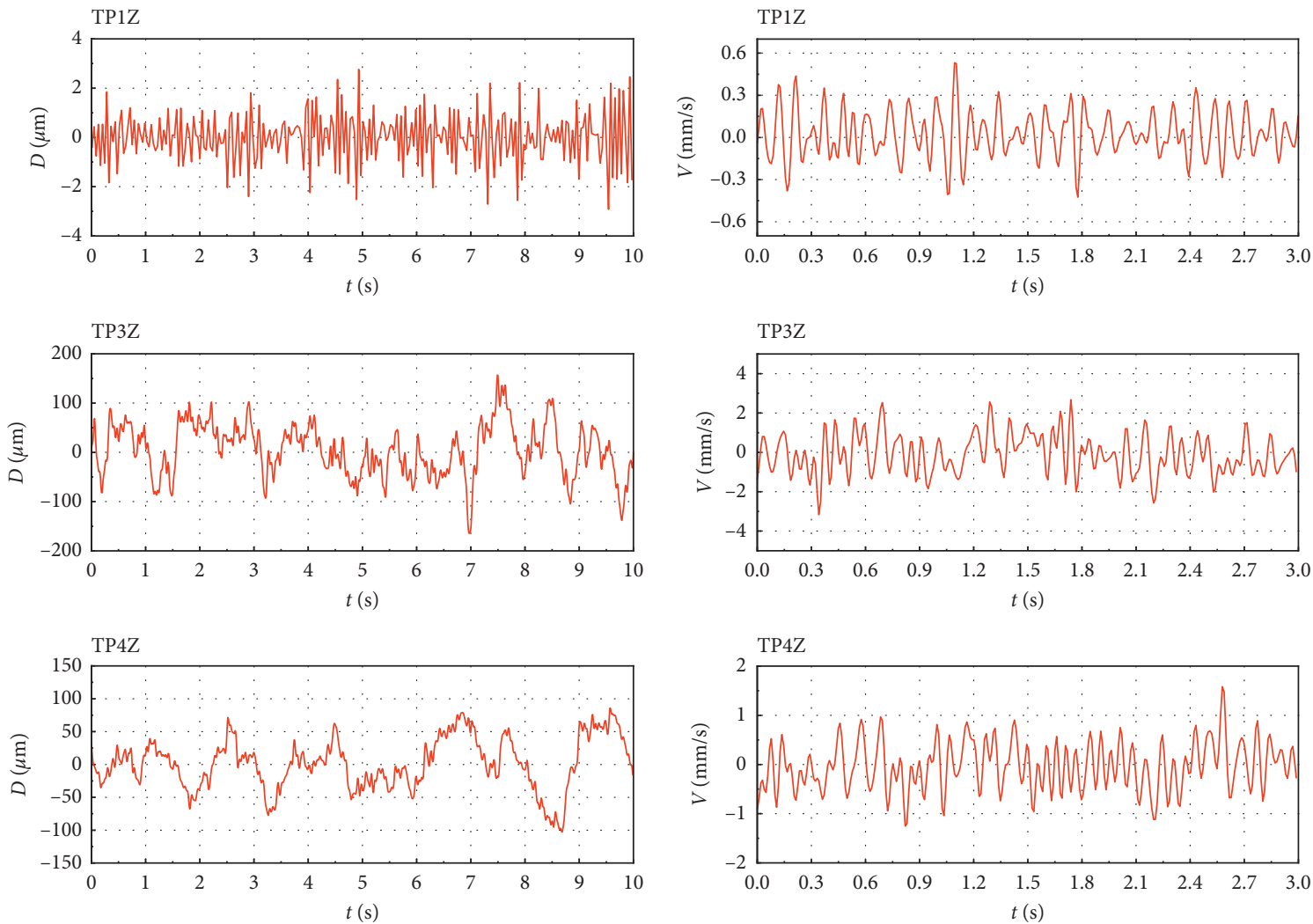

(c)

(d)

Figure 6: Continued. 

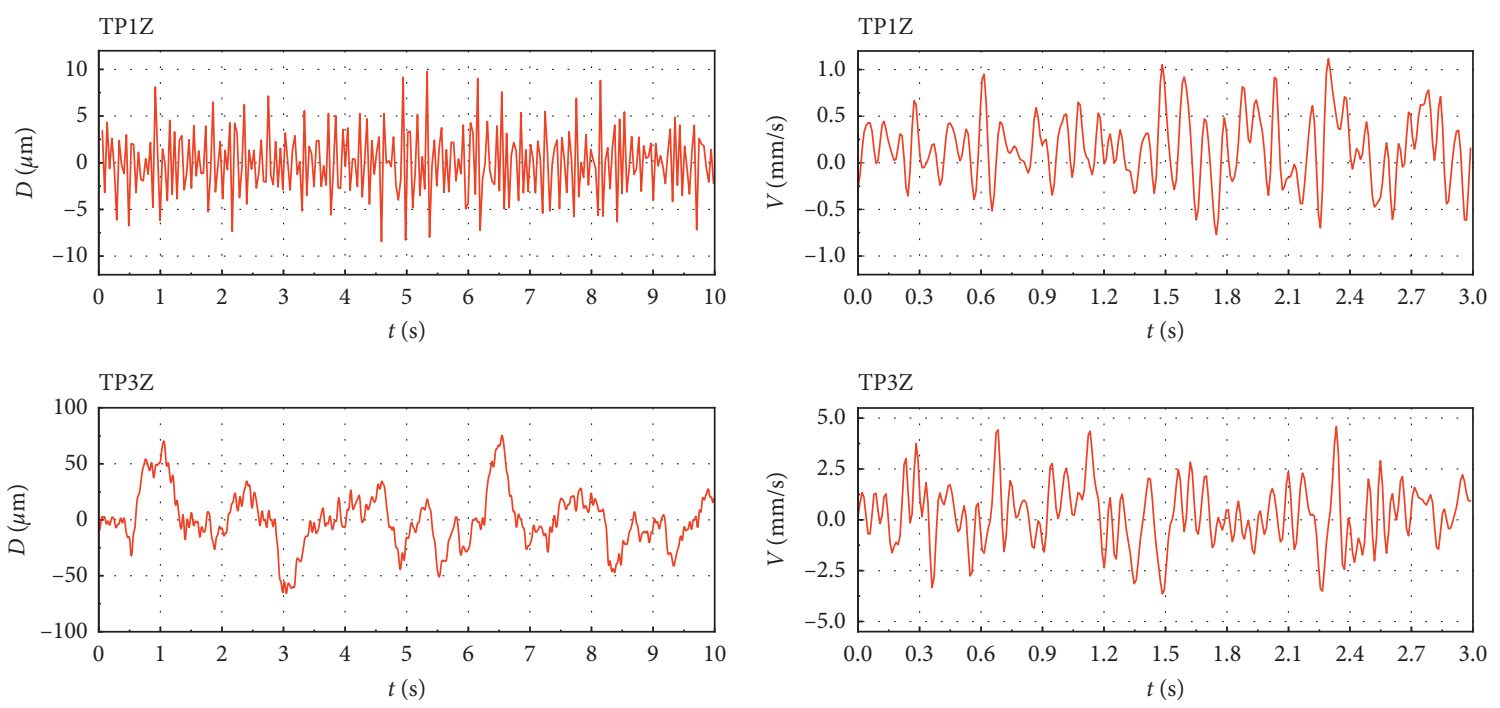

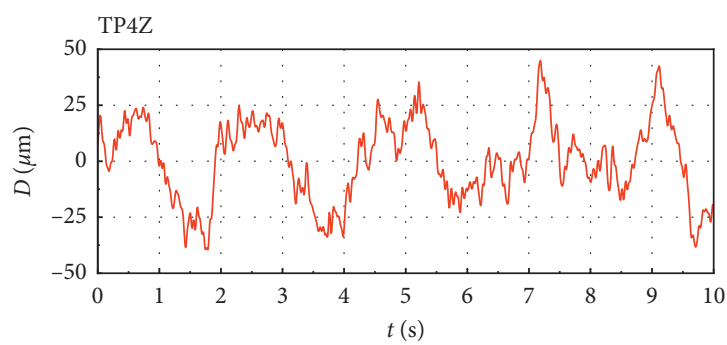

(e)

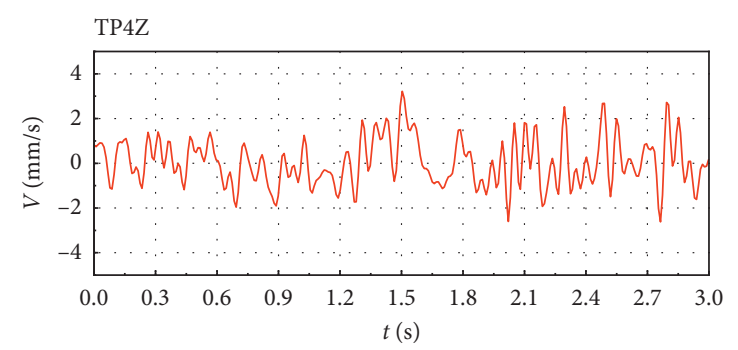

(f)

Figure 6: Time-domain waveform: (a) Vertical vibration displacements and (b) vertical vibration velocities of the crusher in the Linyou power plant. (c) Vertical vibration displacements and (d) vertical vibration velocities of the crusher in the Shangluo power plant. (e) Vertical vibration displacements and (f) vertical vibration velocities of the crusher in the Ezhou power plant.

TABle 3: Maximum displacements and velocities found in vibration tests.

\begin{tabular}{|c|c|c|c|c|c|c|c|}
\hline \multirow{2}{*}{ Power plant } & \multirow{2}{*}{ Location } & \multicolumn{3}{|c|}{$D(\mu \mathrm{m})$} & \multicolumn{3}{|c|}{$V\left(\mathrm{~mm} \cdot \mathrm{s}^{-1}\right)$} \\
\hline & & $X$ & Y & $Z$ & $X$ & Y & $Z$ \\
\hline \multirow{5}{*}{ Linyou power plant } & TP1 & 2.90 & 2.20 & 6.83 & 0.119 & 0.127 & 0.800 \\
\hline & TP2 & 337.10 & 391.37 & 554.82 & 38.497 & 34.689 & 47.962 \\
\hline & TP3 & 352.78 & 356.76 & 543.16 & 33.521 & 36.731 & 47.260 \\
\hline & $\mathrm{TP} 4$ & 137.85 & 99.22 & 219.39 & 4.749 & 1.888 & 5.316 \\
\hline & TP5 & 172.10 & 118.15 & 159.45 & 4.779 & 2.430 & 3.669 \\
\hline \multirow{5}{*}{ Shangluo power plant } & TP1 & 2.44 & 1.96 & 2.75 & 0.371 & 0.167 & 0.529 \\
\hline & TP2 & 137.2 & 52.06 & 154.41 & 2.47 & 1.052 & 2.876 \\
\hline & TP3 & 149.09 & 56.77 & 164.75 & 2.708 & 1.174 & 3.162 \\
\hline & TP4 & 127.74 & 130.93 & 104.94 & 1.354 & 0.587 & 1.581 \\
\hline & TP5 & 154.09 & 82.77 & 138.34 & 1.235 & 0.526 & 1.438 \\
\hline \multirow{5}{*}{ Ezhou power plant } & TP1 & 9.59 & 11.69 & 9.77 & 0.274 & 0.343 & 1.116 \\
\hline & $\mathrm{TP} 2$ & 59.52 & 41.22 & 60.22 & 3.849 & 2.795 & 3.712 \\
\hline & TP3 & 71.36 & 52.46 & 75.38 & 4.684 & 3.215 & 4.582 \\
\hline & TP4 & 29.63 & 16.14 & 44.92 & 1.700 & 0.792 & 3.217 \\
\hline & TP5 & 41.38 & 23.35 & 60.63 & 2.103 & 1.037 & 4.531 \\
\hline
\end{tabular}

safety. The maximum horizontal vibration displacement of the coal crusher body in the Linyou power plant was $391.37 \mu \mathrm{m}$, and the maximum vertical vibration displacement was $554.82 \mu \mathrm{m}$. The maximum horizontal vibration displacement of the coal crusher body in the Shangluo power plant was $149.09 \mu \mathrm{m}$, and the maximum 
TABLE 4: Comparison of measured and allowable values.

\begin{tabular}{|c|c|c|c|c|c|c|c|}
\hline \multirow{2}{*}{$\begin{array}{l}\text { Power } \\
\text { plant }\end{array}$} & \multirow[b]{2}{*}{ Assessment } & \multicolumn{2}{|c|}{ Floor slab $\left(\mathrm{mm} \cdot \mathrm{s}^{-1}\right)$} & \multicolumn{2}{|c|}{ Platform $(\mu \mathrm{m})$} & \multicolumn{2}{|c|}{ Coal crusher $(\mu \mathrm{m})$} \\
\hline & & $\begin{array}{c}\text { Horizontal } \\
\text { direction }\end{array}$ & $\begin{array}{l}\text { Vertical } \\
\text { direction }\end{array}$ & $\begin{array}{c}\text { Horizontal } \\
\text { direction }\end{array}$ & $\begin{array}{c}\text { Vertical } \\
\text { direction }\end{array}$ & $\begin{array}{c}\text { Horizontal } \\
\text { direction }\end{array}$ & $\begin{array}{l}\text { Vertical } \\
\text { direction }\end{array}$ \\
\hline & $\begin{array}{c}\text { Allowable } \\
\text { values }\end{array}$ & 6.4 & 3.2 & 200 & 150 & - & - \\
\hline Linyou & Test values & 0.127 & 0.8 & 172.10 & 219.39 & 391.37 & 534.82 \\
\hline Shangluo & - & 0.371 & 0.529 & 154.09 & 138.34 & 149.09 & 164.75 \\
\hline Ezhou & - & 0.343 & 1.116 & 41.38 & 60.63 & 71.36 & 75.38 \\
\hline
\end{tabular}

vertical vibration displacement was $164.75 \mu \mathrm{m}$. The maximum horizontal vibration displacement of the coal crusher body in the Ezhou power plant was $71.36 \mu \mathrm{m}$, and the maximum vertical vibration displacement was $75.38 \mu \mathrm{m}$. It was found that the vibration displacement of the coal crusher body in the Linyou power plant was 2-3 times the vibration displacement of the top surface of the foundation. This difference was too large, and the horizontal vibration displacement of the foundation exceeded the limit. This indicated that the rigidity of the connection between the machine body and the platform was insufficient, and the vibration displacement of the machine body was too large. This could cause fatigue damage to some rigid connections in the coal crusher. Moreover, the service life of the crusher would be shortened. This is one of the reasons for the serious powder leakage of the coal crusher. The vibration displacements of the coal crusher body and platform in the Shangluo and Ezhou power plants were close, indicating that the rigid connection between the coal crusher and platform in each plant was good. The vibration displacement of the coal crusher body and platform in the Ezhou power plant was smaller than that in the Shangluo power plant, indicating that the vibration displacement of the machine body could be reduced by limiting the displacement of the vibration-isolation platform. Compared to the steel platform, the vibration displacements of the machine body and concrete platform in the Ezhou power plant were smaller. This was mainly related to the greater weight of the concrete platform.

4.2. Vibration-Isolation Efficiency. The vibration-isolation efficiency can be regarded as the amount of reduction in the machine vibration passed to a structure under a deterministic simple harmonic forced vibration load. It can be measured using different indicators, including displacement, velocity, acceleration, and force. According to the "Design code of vibration isolation of auxiliary machine foundation in fossil fuel power plant" (DL/T 5188-2004) [17], a vibrationisolated foundation is assumed to be a system with a single degree of freedom. The vibration-isolation efficiency can be calculated using the machine's disturbance frequency and the natural frequency of the vibration-isolation system. However, the calculation formula for the vibration-isolation efficiency does not include factors such as the displacement, velocity, and acceleration, making it difficult to measure the vibration-isolation efficiency when the machine is running. In order to facilitate on-site measurements, this test measured the vibration-isolation efficiency based on the degree of attenuation of the dynamic response before and after the vibration isolation [18].

In this test, the working frequency of the coal crusher was $12.38 \mathrm{~Hz}(743 \mathrm{r} / \mathrm{min})$, which was an intermediate frequency vibration [19]. Therefore, the velocities of the spring vibration isolator were used to calculate the vibration-isolation efficiency:

$$
\begin{gathered}
\eta_{i}=1-\frac{V_{i 2}}{V_{i 1}}, \\
\eta=\frac{\sum_{i=1}^{n} \eta_{i}}{n}
\end{gathered}
$$

where $V_{1}$ is the upper velocity of the spring vibration isolator and $V_{2}$ is the lower velocity of the spring vibration isolator.

The vibration-isolation efficiency of a single spring vibration isolator could be calculated using equations (1) and (2). Then, the vibration-isolation efficiencies of multiple sets of spring vibration isolators were calculated and averaged to obtain the vibration-isolation efficiency of the spring vibration-isolation system. The results are listed in Table 5.

The "Technical code for the design of civil structure of fossil-fired power plant" (DL 5022-2012) [15] stipulates that if the vibration-isolation efficiency of a spring vibrationisolated foundation is greater than or equal to $90 \%$, the support structure below the vibration isolation device of a coal crusher does not require dynamic calculation. The design value of vibration-isolation efficiency for the coal crusher systems in the three power plants was $90 \%$. As seen in Table 4, the vibration-isolation efficiencies of the three power plants did not meet the code requirements. The vibration-isolation efficiency of the spring vibration-isolation system used in the Linyou power plant was the lowest, which was closely related to the connection between the platform and the machine. Compared to the other two power plants, the spring vibration-isolation system used in the Ezhou 
TABLE 5: Vibration-isolation efficiency.

\begin{tabular}{|c|c|c|c|c|c|c|c|c|c|}
\hline Power plant & Physical quantity & A & B & $\mathrm{C}$ & $\mathrm{D}$ & $\mathrm{E}$ & $\mathrm{F}$ & G & $\mathrm{H}$ \\
\hline \multirow{4}{*}{ Linyou power plant } & $V_{1}(\mathrm{~mm} / \mathrm{s})$ & 4.523 & 3.203 & 4.215 & 5.816 & 2.613 & 3.158 & 2.745 & - \\
\hline & $V_{2}(\mathrm{~mm} / \mathrm{s})$ & 1.211 & 0.856 & 1.033 & 1.787 & 1.029 & 0.912 & 0.924 & - \\
\hline & $\eta_{i}$ & $73.23 \%$ & $73.28 \%$ & $75.49 \%$ & $69.27 \%$ & $60.62 \%$ & $71.12 \%$ & $66.34 \%$ & - \\
\hline & $\eta$ & \multicolumn{8}{|c|}{$69.91 \%$} \\
\hline \multirow{4}{*}{ Shangluo power plant } & $V_{1}(\mathrm{~mm} / \mathrm{s})$ & 2.359 & 2.398 & 2.204 & 1.956 & 1.543 & 1.789 & 1.932 & 1.879 \\
\hline & $V_{2}(\mathrm{~mm} / \mathrm{s})$ & 0.635 & 0.692 & 0.632 & 0.477 & 0.456 & 0.422 & 0.476 & 0.461 \\
\hline & $\eta_{i}$ & $73.08 \%$ & $71.14 \%$ & $71.32 \%$ & $75.61 \%$ & $70.44 \%$ & $76.41 \%$ & $75.36 \%$ & $75.47 \%$ \\
\hline & $\eta$ & \multicolumn{8}{|c|}{$73.59 \%$} \\
\hline \multirow{4}{*}{ Ezhou power plant } & $V_{1}(\mathrm{~mm} / \mathrm{s})$ & 4.625 & 4.568 & 4.895 & 3.282 & 4.518 & - & - & - \\
\hline & $V_{2}(\mathrm{~mm} / \mathrm{s})$ & 0.954 & 1.089 & 0.978 & 0.918 & 1.035 & - & - & - \\
\hline & $\eta_{i}$ & $79.37 \%$ & $76.16 \%$ & $80.02 \%$ & $72.03 \%$ & $77.09 \%$ & - & - & - \\
\hline & $\eta$ & \multicolumn{8}{|c|}{$76.93 \%$} \\
\hline
\end{tabular}

power plant with a concrete platform was more efficient. The construction of a finite element model of the coal crusher chamber is recommended for a dynamic analysis.

\section{Conclusions}

In this study, the vibration behaviors of the coal crushers in three thermal power plants were investigated using field tests and assessments. The major conclusions are summarized as follows:

(1) The tested coal crusher foundations met the vibration safety requirements, except for the vertical vibration displacement of the coal crusher in the Linyou power plant. The vibration displacement of the coal crusher in the Linyou power plant was too large, and the rigidity of the connection between the machine body and the platform was insufficient, which could result in fatigue damage to some rigid connections in the coal crusher. Moreover, the service life of the crusher will be shortened. Therefore, it is recommended that the connection rigidity be increased.

(2) The vibration-isolation efficiency of each spring vibration-isolation system could be measured using the dynamic responses of the upper and lower ends of the spring. This method was simple and easy to implement.

(3) Although there is a lack of relevant guidelines on the vibration displacement of a machine body, controlling the vibration displacement of the platform could be used to reduce the vibration displacement of the coal crusher body. Compared to the steel platform, the vibration displacements of the concrete platforms were smaller, and their vibration-isolation efficiencies were greater. The construction of a finite element model of a coal crusher chamber is recommended for a dynamic analysis.

\section{Data Availability}

The data used to support the findings of this study are available from the corresponding author upon request.

\section{Conflicts of Interest}

The authors declare that they have no conflicts of interest.

\section{Acknowledgments}

This work was funded by the project of the Shaanxi Province Key Research and Development Program on Industry Innovation Chain (2018ZDCXL-SF-03-03-01).

\section{References}

[1] G. W. Housner, L. A. Bergman, T. K. Caughey et al., "Structural control: past, present, and future," Journal of Engineering Mechanics, vol. 123, no. 9, pp. 897-971, 1997.

[2] S. K. Lapin, "Transfer of vibrations from machine foundations to adjacent foundations supporting buildings and structures," Soil Mechanics and Foundation Engineering, vol. 46, no. 5, pp. 202-206, 2009.

[3] L. H. Zhu, J. Dai, and G. L. Bai, "Sensor placement optimization of vibration test on medium-speed mill," Shock and Vibration, vol. 2015, Article ID 690196, 9 pages, 2015.

[4] M.-H. Shih, W.-P. Sung, and C.-L. Chen, "Vibration control and shock absorption techniques for $\mathrm{Hi}$-Tech manufacturing plants," The Structural Design of Tall and Special Buildings, vol. 21, no. 7, pp. 505-523, 2012.

[5] Y. Kim, C.-W. Kim, S. Lee, and H. Park, "Dynamic modeling and numerical analysis of a cold rolling mill," International Journal of Precision Engineering and Manufacturing, vol. 14, no. 3, pp. 407-413, 2013.

[6] Y. X. Wu and J. A. Duan, "Frequency modulation of highspeed mill chatter," Journal of Materials Processing Technology, vol. 129, no. 1-3, pp. 148-151, 2002.

[7] Z. Y. Liang, Finite Element Dynamic Analysis of Dynamic Machine Foundation considering Soil-Structure Interaction, Xi'an University of Architecture and Technology, Xi'an, China, 2018, in Chinese.

[8] J. B. Liu, Z. Y. Wang, K. F. Zhang, and Y. X. Pei, “3D finite element analysis of large dynamic machine foundation considering soil-structure interaction," Engineering Mechanics, vol. 19, no. 3, pp. 34-38, 2002, in Chinese.

[9] L. H. Zhu, G. L. Bai, Y. L. Peng, F. J. Zhang, and X. L. Sun, "Vibration test and shock absorption research on mediumspeed mill in thermal power plants," Journal of Building Structures, vol. 34, no. 5, pp. 43-51, 2013, in Chinese.

[10] J. Li, Z. Zhang, H. Xu, and Z. Feng, "Dynamic characteristics of the vibratory roller test-bed vibration isolation system: 
simulation and experiment," Journal of Terramechanics, vol. 56, pp. 139-156, 2014.

[11] L. K. Wang, A. W. GE, and N. N. Zhang, "Vibration test and vibration control study of a screening building," World Earthquake Engineering, vol. 32, no. 3, pp. 185-192, 2016, in Chinese.

[12] G. Gazetas, "Analysis of machine foundation vibrations: state of the art," International Journal of Soil Dynamics and Earthquake Engineering, vol. 2, no. 1, pp. 2-42, 1983.

[13] China Planning Press, Code for Design of Dynamic Machine Foundation (GB50040-1996), China Planning Press, Beijing, China, 1997.

[14] H. Zhou, L. Sun, and F. Xing, "Free vibration of taut cable with a damper and a spring," Structural Control and Health Monitoring, vol. 21, no. 6, pp. 996-1014, 2014.

[15] China Planning Press, Technical Code for the Design of Civil Structure of Fossil-Fired Power Plant (DL5022-2012), China Planning Press, Beijing, China, 2012.

[16] China Planning Press, Code for Design of Building and Structure of Coal Mine of Preparation Plant (GB50583-2010), China Planning Press, Beijing, China, 2010.

[17] China Electric Power Press, Design Code of Vibration Isolation of Auxiliary Machine Foundation in Fossil Fuel Power Plant (DL/T5188-2004), China Electric Power Press, Beijing, China, 2004.

[18] T. D. Le, M. T. N. Bui, and K. K. Ahn, "Improvement of vibration isolation performance of isolation system using negative stiffness structure," IEEE/ASME Transactions on Mechatronics, vol. 21, no. 3, pp. 1561-1571, 2016.

[19] B. Mace, W. Desmet, and B. Pluymers, "Mid-Frequency methods in sound and vibration-Part A," Journal of Sound and Vibration, vol. 332, no. 8, pp. 1895-1896, 2013. 